JOÃO LUIZ PONCE MAIA

SEPARAÇÃO E CAPTURA DO DIÓXIDO DE CARBONO EM INSTALAÇÕES MARÍTIMAS DE PRODUÇÃO DE PETRÓLEO 
JOÃO LUIZ PONCE MAIA

\section{SEPARAÇÃO E CAPTURA DO DIÓXIDO DE CARBONO EM INSTALAÇÕES MARÍTIMAS DE PRODUÇÃO DE PETRÓLEO}

Tese apresentada à Escola Politécnica da Universidade de São Paulo para obtenção do Título de Professor Doutor junto ao Departamento de Engenharia Hidráulica e Sanitária 
JOÃO LUIZ PONCE MAIA

SEPARAÇÃO E CAPTURA DO DIÓXIDO DE CARBONO EM INSTALAÇÕES MARÍTIMAS DE PRODUÇÃO DE PETRÓLEO

\author{
Tese apresentada à Escola Politécnica \\ da Universidade de São Paulo para \\ obtenção do Título de Professor Doutor \\ junto ao Departamento de Engenharia \\ Hidráulica e Sanitária \\ Área de Concentração: \\ Engenharia Hidráulica, Recursos \\ Hídricos \\ Orientador: Prof. Livre-Docente \\ Prof Dr. Mario Thadeu L. de Barros \\ Co-Orientadora: Profa. Livre-Docente \\ Profa. Dra. Patrícia H. L. dos Santos \\ Matai
}


AUTORIZO A REPRODUÇÃO E A DIVULGAÇÃO TOTAL OU PARCIAL DESTE TRABALHO, POR QUALQUER MEIO CONVENCIONAL OU ELETRÔNICO, PARA FINS DE ESTUDO E PESQUISA, DESDE QUE CITADA A FONTE.

FICHA CATALOGRÁFICA

Maia, João Luiz Ponce

Separação e captura do dióxido de carbono em instalações marítimas de produção de petróleo / J.L.

P. Maia. -- São Paulo, 2007. $216 \mathrm{p}$.

Tese (Doutorado) - Escola Politécnica da Universidade de São Paulo. Departamento de Engenharia Hidráulica e Sanitária.

1.Efeito estufa 2.Dióxido de carbono 3.Petróleo 4.Separação de $\mathrm{CO}_{2}$ 5.Captura de $\mathrm{CO}_{2}$ 6.Emissão atmosférica 7.Armazenamento geológico I.Universidade de São Paulo. Escola Politécnica. Departamento de Engenharia Hidráulica e Sanitária II.t. 


\section{DEDICATÓRIA}

Dedico esta tese aos meus pais, irmãos, esposa e minha filha, pelo incentivo, compreensão e paciência que tiveram comigo, ao longo destes últimos três anos. 


\section{AGRADECIMENTOS}

Ao Prof. Dr. Mario Thadeu L. M. Barros pelo seu incentivo e visão, que me foram muito úteis para o desenvolvimento e conclusão deste trabalho.

À Profa. Dra. Patrícia H. L. dos Santos Matai também pelo incentivo, apoio e pelos comentários realizados nos últimos dois anos.

Aos meus pais Jorge Maia da Silva e Maria Helena Ponce Maia da Silva, minha esposa Beatriz Tavares Pereira Ponce Maia e minha filha Helena Ponce Maia, pelo carinho e incentivo que me deram, e a todos que colaboraram direta ou indiretamente, na execução desta tese. 


\section{RESUMO}

A necessidade atual do mercado brasileiro para aumentar a oferta de gás incentiva a comunidade científica nacional no desafio de desenvolvimento de novas rotas tecnológicas, visando aumentar o aproveitamento do gás natural. Tal desafio é acompanhado por uma demanda mundial dos países signatários do Protocolo de Quioto ${ }^{1}$ (ratificado em 2005) para a redução das emissões de gases de efeito estufa. Apesar de o Brasil não apresentar nenhuma meta de redução, no primeiro período deste Protocolo (2008 a 2012), o setor do petróleo (atividade de E\&P), através de suas companhias operadoras, que atuam no país, já estabeleceram metas corporativas para emissão evitada de gases de efeito estufa, em suas instalações de produção (maior predominância das unidades marítimas de produção).

O presente trabalho aborda a análise técnica e econômica de um processo proposto de separação e captura de dióxido de carbono $\left(\mathrm{CO}_{2}\right)$, através de estudo de caso (Primeira e Segunda Proposição) de simulação de processo, em uma instalação marítima de produção de petróleo, comparativamente a sua ausência (Caso Base).

A Primeira Proposição considera a separação e a captura do $\mathrm{CO}_{2}$ oriundo tanto do gás natural produzido, quanto do gás de queima de uma turbina a gás.

A Segunda Proposição considera a separação e a captura do $\mathrm{CO}_{2}$ oriundo somente do gás natural produzido.

Até o momento, no Brasil, ainda não foram desenvolvidas tecnologias adequadas para a captura do $\mathrm{CO}_{2}$, em instalações marítimas de produção de petróleo. Adicionalmente a regulação atual (Portaria $\mathrm{n}^{\circ} 104 / 2002$ da $\mathrm{ANP}^{2}$ ) limita o potencial de utilização do $\mathrm{CO}_{2}$ que existe na composição do gás natural comercializado no país, pelo fato de não diferenciar em sua especificação técnica, os usos deste importante combustível.

Os resultados obtidos nesta tese, com a utilização de simulador de processo de uso comercial mostraram emissões evitadas de $\mathrm{CO}_{2}$ para atmosfera de $55 \%$ (caso Segunda Proposição que apresentou maior viabilidade econômica), em relação ao resultado obtido para o Caso Base. Este relevante resultado equivale a uma emissão evitada de aproximadamente $241 \times 10^{3}$ t/ano, para uma única unidade piloto proposta.

\footnotetext{
${ }^{1}$ Acordo a nível internacional por parte de 175 países signatários no mundo, que visando a estabilização da concentração de gases de efeito estufa (GEE) na terra, estabeleceu, em seu primeiro período de vigência (20082012), para países desenvolvidos metas de redução de suas emissões de GEE.

${ }^{2}$ Agência Nacional do Petróleo, Gás Natural e Biocombustíveis.
} 
De acordo com o estudo de análise econômica apresentado, a Segunda Proposição (VPL US\$15,3 x $10^{6}$ ) foi melhor do que a da Primeira Proposição (VPL: US\$13,9 x 106 ) ambos usando o Caso Base como referência.

Dentre os ganhos esperados com o uso desta nova tecnologia destacam-se: redução do consumo interno e das perdas de gás natural, emissão evitada de $\mathrm{CO}_{2}$ e hidrocarbonetos para a atmosfera, além do aumento das práticas de armazenamento de gás e $\mathrm{CO}_{2}$, em reservatórios geológicos depletados ${ }^{3}$ de petróleo.

Estima-se que num cenário futuro, com a implantação deste novo processo proposto, em instalações marítimas de produção de petróleo, uma relevante contribuição de emissões evitadas de gases de efeito estufa possa ocorrer na área de E\&P de petróleo no Brasil.

\footnotetext{
${ }^{3}$ Estado em que o reservatório de petróleo apresenta baixa energia de pressão, o que leva a interrupção da sua produção, considerando as tecnologias de recuperação implantadas no projeto.
} 


\begin{abstract}
The current Brazilian market needs to increase the natural gas supply to incentive the national scientific community to the challenge of developing new technologies routes aiming increase the utilization of the produced natural gas. Such challenge is followed by a world demand from signatory countries of the Kyoto Agreement (ratified in 2005) to reduce the greenhouse gas emissions. In spite of, the Brazil does not have any reduction goal, in the first period (2008 to 2012) the oil sector (E\&P activity), by their oil operators companies that works in our country, has already established corporative goals to avoided greenhouse gas emissions in their production facilities (bigger predominance of offshore production unities).

The present work approaches the economic and technical evaluation of a carbon dioxide $\left(\mathrm{CO}_{2}\right)$ separation and capture proposal process (First and Second Proposal Case) comparatively your absence (Base Case).

The First Case consider the $\mathrm{CO}_{2}$ separation and capture both the produced gas and exhausted gases of one turbine driven by gas.

The Second Case consider only the $\mathrm{CO}_{2}$ separation and capture from the produced gas.

At the present, in Brazil, it has not been developed yet suitable technologies, for such use, and the $\mathrm{CO}_{2}$ is normally disposal to the atmosphere. Moreover, the present Regulation (104/2002 ANP Decree) limit the potential of $\mathrm{CO}_{2}$ use existing in the gas composition that is marketed in the country, due to not differentiate the uses of this important fuel.

The results obtained of this thesis, by using a process simulator of commercially use showed $\mathrm{CO}_{2}$ avoided emissions of $55 \%$ to the atmosphere (Second Proposal Case that shows the best economic evaluation) related to the result obtained from the Base Case. This relevant result is equivalent in mass flow, to the avoidance emission of roughly $241 \times 10^{3}$ tons per year, for a single pilot unity proposal.

According the economic evaluation study, the Second Proposal Case (VPL:US\$ $15,3 \times 10^{6}$ ) was better than the First Case (VPL: US\$13,9 $\times 10^{6}$ ), using the Case Base as reference.

Within the benefits expected with the use of this new technology are the following: reduction both the internal gas consumption and natural gas losses (atmospheric disposal), emissions avoided of $\mathrm{CO}_{2}$ and hydrocarbons, beyond the increase of $\mathrm{CO}_{2}$ and gas storage practices in offshore depleted oil fields.
\end{abstract}


It is estimated, in future scenery, with the implantation of this new proposal process in offshore production unities, relevant contribution of avoided greenhouse gases emissions can occur in oil E\&P tasks in Brazil. 


\section{LISTA DE FIGURAS}

Figura 2.1- Reservatório produtor de óleo e de gás

Figura 2.2- Distribuição percentual do forçamento radioativo dos GEE

Figura 2.3- Emissões e Previsões de $\mathrm{CO}_{2}$ no mundo de origem fóssil $\left(10^{6} \mathrm{~m}^{3}\right)$ no período de 2003 a 2030. 48

Figura 2.4- Diagrama de blocos da estrutura global de produção de gás no Brasil 49

Figura 2.5- Emissões de GEE da Petrobras (2004-2006) em t CO2 eq. por ano.. 50

Figura 2.6- Distribuição percentual das emissões de $\mathrm{CO}_{2}$ equivalente da Petrobras por atividades (2004) 50

Figura 2.7- Processo de Transferência de RCE ................................................................... 54

Figura 2.8- Estrutura esquemática do ciclo de um projeto MDL ..................................... 56

Figura 3.1- Estrutura básica do Processo de Captura e Armazenamento de $\mathrm{CO}_{2}$............... 66

Figura 4.1- Representação esquemática de uma turbina a gás natural .............................. 70

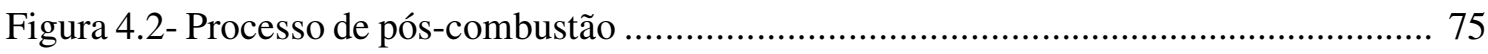

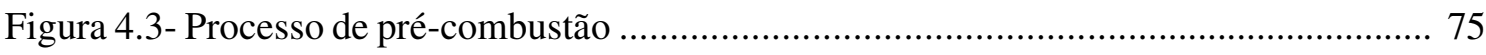

Figura 4.4- Processo de oxi-combustão (denitrificação) ...................................................... 76

Figura 4.5- Estrutura molecular de aminas comerciais ....................................................... 78

Figura 4.6- Fluxograma esquemático do processo de absorção com aminas ...................... 79

Figura 4.7- Representação esquemática de uma membrana polimérica .............................. 82

Figura 5.1- Estrutura esquemática de um sistema marítimo de produção

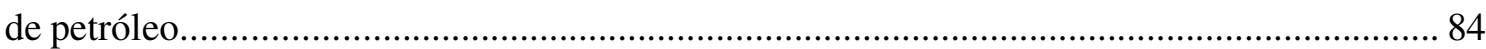

Figura 5.2- Estrutura esquemática de processo de uma unidade marítima de produção de

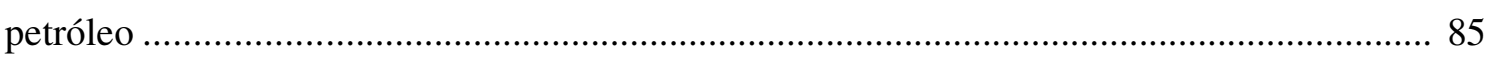

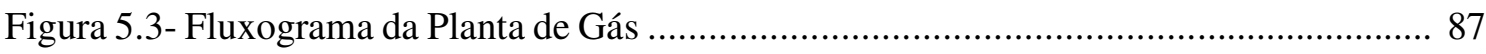

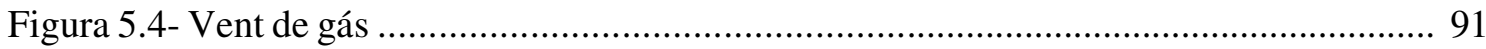

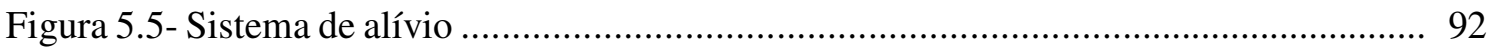

Figura 5.6- Desenho esquemático de um ejetor para recuperação de $\mathrm{CO}_{2}$ com fluido motriz

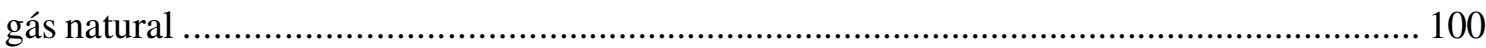

Figura 5.7- Modelo da tela de resultado do programa Ejetor ....................................... 101

Figura 5.8- Configuração básica de um sistema de compressão de gás .............................. 102

Figura 6.1- Emissão de gases de combustão (turbina a gás natural) .............................. 104

Figura 6.2- Emissão atmosférica na unidade de remoção de $\mathrm{CO}_{2}$.................................. 104 
Figura 6.3- Representação esquemática da malha de transferência e recebimento

de gás 106

Figura 6.4- Representação esquemática da cadeia do gás natural e a aplicação da Portaria ${ }^{\circ} 104 / 2002$ da ANP. 110

Figura 7.1- Representação esquemática do local para implantação do projeto 117

Figura 7.2- Fluxograma esquemático do caso base

Figura 7.3- Fluxograma esquemático do sistema de geração de energia elétrica.

(Simulador Hysys)

Figura 7.4- Fluxograma esquemático do sistema de separação do $\mathrm{CO}_{2}$ com uma torre contactora (simulador Hysys) 128

Figura 7.5- Distribuição percentual das emissões atmosféricas globais (Caso Base) 130

Figura 7.6- Fluxograma esquemático do Caso Primeira Proposição ( $1^{\mathrm{a}}$ Parte $)$ 134

Figura 7.7- Fluxograma esquemático do Caso Primeira Proposição (2 $2^{\mathrm{a}}$ Parte) 135

Figura 7.8- Fluxograma esquemático do sistema de captação e pré-tratamento dos gases de combustão

Figura 7.9- Fluxograma esquemático do sistema de separação híbrida do $\mathrm{CO}_{2}$ da Primeira Proposição 138

Figura 7.10- Fluxograma esquemático do sistema de armazenamento do $\mathrm{CO}_{2}$ 140

Figura 7.11- Distribuição percentual volumétrica das emissões atmosféricas globais da Primeira Proposição 142

Figura 7.12- Fluxograma esquemático do Caso Segunda Proposição ( $1^{\text {a }}$ Parte $)$...................145

Figura 7.13- Fluxograma esquemático do Caso Segunda Proposição ( $2^{\mathrm{a}}$ Parte $)$...................146

Figura 7.14- Fluxograma esquemático do sistema de separação híbrida do $\mathrm{CO}_{2}$ da Segunda Proposição

Figura 7.15- Distribuição percentual volumétrica das emissões atmosféricas globais da

Segunda Proposição

Figura 7.16- Emissões atmosféricas por fonte emissora $\left(10^{3} \mathrm{t} \mathrm{CO}_{2}\right.$ eq./ano)

Figura 7.17- Emissões atmosféricas dos Casos Base, Primeira e Segunda Proposição $\left(10^{5} \mathrm{t} \mathrm{CO}_{2}\right.$ eq./ano $)$ 150

Figura 8.1- Estrutura básica de um Programa de Análise Econômica 152

Figura 8.2- Curva da produção do gás produzido e de gás lift da Primeira Proposição..........154

Figura 8.3- Estrutura do balanço de massa da Primeira Proposição 155 


\section{LISTA DE TABELAS}

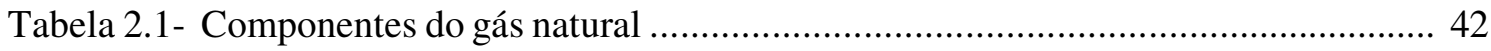

Tabela 2.2- Emissões atmosféricas na indústria do petróleo ................................................ 45

Tabela 2.3- Valores de GWP dos gases de efeito estufa em função do tempo ................... 46

Tabela 2.4- Custos de transação inerente ao ciclo de projetos MDL .................................. 60

Tabela 2.5- Custos mínimos de transação associados com o ciclo de um projeto MDL .........60

Tabela 3.1- Resultados comparativos do custo evitado e da taxa de captura do $\mathrm{CO}_{2}$

entre duas alternativas de geração termelétrica a gás natural .............................................69

Tabela 4.1- Composição típica de gases de combustão de uma turbina a gás ...................... 72

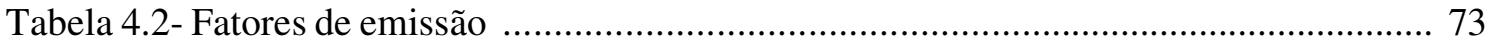

Tabela 5.1- Estimativa da evolução das emissões de $\mathrm{CO}_{2}$ nas instalações marítimas de produção de petróleo do Rio de Janeiro no período 2002-2006......................................... 94

Tabela 5.2- Blocos de entrada do simulador de processo Hysys ..................................... 96

Tabela 6.1- Especificação proposta para consumo próprio (uso energético) em

instalações marítimas de produção de petróleo ...................................................................... 111

Tabela 6.2- Especificação proposta para consumo próprio (uso não energético) em

instalações marítimas de produção de petróleo ............................................................. 112

Tabela 7.1- Dados de entrada da simulação do Caso Base .................................................. 122

Tabela 7.2- Emissões atmosféricas globais do Caso Base …........................................... 130

Tabela 7.3- Dados de entrada do caso Primeira Proposição ................................................ 131

Tabela 7.4- Principais correntes e respectivas variáveis do sistema de captação e pré-tratamen-

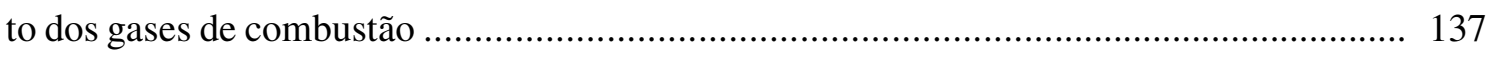

Tabela 7.5- Emissões atmosféricas globais do caso Primeira Proposição ......................... 142

Tabela 7.6- Dados de entrada da simulação do caso Segunda Proposição ...........................143

Tabela 7.7- Emissões atmosféricas globais do caso Segunda Proposição ......................... 149

Tabela 8.1- Estimativa do custo total de investimento do caso Primeira Proposição (CAPEX)

Tabela 8.2- Estimativa do custo operacional global do caso Primeira Proposição (OPEX) ..154

Tabela 8.3- Dados comparativos de vazão entre o caso Base e a Primeira Proposição para o $1^{\circ}$ ano.

Tabela 8.4- Estimativa do custo total de investimento do caso Segunda Proposição (CAPEX) 
Tabela 8.5- Estimativa do custo operacional global do caso Segunda Proposição (OPEX). 158

Tabela 8.6- Resultados econômicos da Primeira Proposição ............................................ 160

Tabela 8.7- Resultados econômicos da Segunda Proposição ............................................ 161 


\section{LISTA DE ABREVIATURAS E SIGLAS}

A

$\mathrm{ACB}$

ACQ

ANP

AND

B

BA

$\mathrm{BP}$

BEN

$\mathrm{BM} \& \mathrm{~F}$

BVRJ

CAPEX

CCS

$\mathrm{CCP}$

$\mathrm{CDM}$

CER

CSLF

CSLF

COP3

$\mathrm{CO}_{2}$ ecap

$\mathrm{CO}_{2}$ eref

COEcap

COEref

CONAMA

COFINS

CAPEX

DCP

DEA

DJSI

$\mathrm{E}$

$\mathrm{ECO}_{2}$
Taxa de Atividade

Vazão de Gás Combustível (Isento $\mathrm{CO}_{2}$ ) Queimado nas Turbinas a Gás

Vazão de gás (isento de $\mathrm{CO}_{2}$ ) de contingência queimado

Agência Nacional do Petróleo, Gás Natural e Biocombustíveis

Autoridade Nacional Designada

Vazão volumétrica de gás combustível de alta pressão para uso energético, Isento de $\mathrm{CO}_{2}$

Bahia

British Petroleum

Balanço Energético Nacional

Bolsa de Mercadorias \& Futuros

Bolsa de Valores do Rio de Janeiro

Capital Expenditure

Carbon Dioxide Capture and Storage

Carbon Dioxide Capture Project

Clean Develop Mechanism

Certified Emissions Register

Carbon Sequestration Leadership Fórum

Carbon Sequestration Leadership Fórum

$3^{\mathrm{a}}$ Reunião da Conferência das Partes

Emissões de $\mathrm{CO}_{2}$ no Cenário de Captura,

Emissões de $\mathrm{CO}_{2}$ no Cenário de Referência

Custo da Eletricidade Gerada Com a Captura do $\mathrm{CO}_{2}$

Custo da Eletricidade Gerada Sem a Captura do $\mathrm{CO}_{2}$

Conselho Nacional do Meio Ambiente

Contribuição Federal

Custo de Investimento de Capital

Documento de Concepção de Projeto

Dietanolamina

Down Jones Sustaintability Index

Emissões

Emissão do $\mathrm{CO}_{2}$ 


\begin{tabular}{|c|c|}
\hline ECGEE & Emissão Gasosa do Componente de Gás de Efeito Estufa \\
\hline EGEE & missões Atmosféricas dos Gases de Efeito Estufa \\
\hline EgáscombsCO ${ }_{2}$ alb & $\begin{array}{l}\text { Emissão do Gás Combustível, Uso Não Energético, Isento de } \mathrm{CO}_{2} \\
\text { Queimado no Sistema de Alívio, no Caso Base }\end{array}$ \\
\hline EgáscontsCO $\mathrm{CO}_{2} \mathrm{alb}$ & $\begin{array}{l}\text { Emissão do } \mathrm{CO}_{2} \text { Gerado pela Combustão do Gás Combustível, Isento } \\
\mathrm{CO}_{2} \text {, no Sistema de Alívio, em situações de Contingência, no Caso } \\
\text { Base }\end{array}$ \\
\hline EgelsCO $\mathrm{C}_{2} \mathrm{~b}$ & $\begin{array}{l}\text { Emissão Gerada pela Combustão do Gás Combustível de Uso } \\
\text { Energético, Isento de } \mathrm{CO}_{2} \text {, no Caso Base }\end{array}$ \\
\hline EgelsCO ${ }_{2} \mathrm{p} 1$ & $\begin{array}{l}\text { Emissão do } \mathrm{CO}_{2} \text { Gerada pela Combustão do Gás Combustível de Uso } \\
\text { Energético, Isento de } \mathrm{CO}_{2} \text {, na Primeira Proposição }\end{array}$ \\
\hline EgelCO$_{2} \mathrm{~b}$ & $\begin{array}{l}\text { Emissão do } \mathrm{CO}_{2} \text { Existente no Gás Combustível de Uso Energético do } \\
\text { Caso Base }\end{array}$ \\
\hline $\mathrm{EgelCO}_{2} p 1$ & $\begin{array}{l}\text { Emissão do } \mathrm{CO}_{2} \text { Existente na Composição do Gás Combustível de Uso } \\
\text { Energético, da Primeira Proposição }\end{array}$ \\
\hline EgnealCO ${ }_{2} \mathrm{p} 1$ & $\begin{array}{l}\text { Emissão do } \mathrm{CO}_{2} \text { Existente no Gás Combustível de Uso Não } \\
\text { Energético, para o Sistema de Alívio, da Primeira Proposição }\end{array}$ \\
\hline EgnealsCO $_{2} \mathrm{p} 1$ & $\begin{array}{l}\text { Emissão do } \mathrm{CO}_{2} \text { a partir da Combustão do Gás Combustível de Uso } \\
\text { Não Energético, Isento de } \mathrm{CO}_{2} \text {, da Primeira Proposição }\end{array}$ \\
\hline Ehcgásselvab & $\begin{array}{l}\text { Emissão de Hidrocarbonetos, Isento de } \mathrm{CO}_{2} \text { do Gás de Selagem dos } \\
\text { Compressores, Ventilado para Atmosfera, no Caso Base }\end{array}$ \\
\hline Ehcgásnesvab & $\begin{array}{l}\text { Emissão de Hidrocarbonetos, Isento de } \mathrm{CO}_{2} \text { do Gás Combustível Não } \\
\text { Energético, Ventilado para Atmosfera, no Caso Base }\end{array}$ \\
\hline EIA & Energy Information Administration \\
\hline EOD & Entidade Operacional Designada \\
\hline $\mathrm{ECO}_{2}$ gáscombalb & $\begin{array}{l}\text { Emissão do } \mathrm{CO}_{2} \text { Existente na Composição do Gás Queimado em } \\
\text { Situação de Contingência, no Caso Base }\end{array}$ \\
\hline $\mathrm{ECO}_{2}$ gásnevab & $\begin{array}{l}\text { Emissão do } \mathrm{CO}_{2} \text { oriundo do gás combustível não energético para vent } \\
\text { atmosférico, no Caso Base }\end{array}$ \\
\hline $\mathrm{ECO}_{2}$ gáscontalb & $\begin{array}{l}\text { Emissão do } \mathrm{CO}_{2} \text { Existente na Composição do Gás Queimado em } \\
\text { Situação de Contingência, no Caso base }\end{array}$ \\
\hline $\mathrm{ECO}_{2}$ gásselvab & $\begin{array}{l}\text { Emissão de } \mathrm{CO}_{2} \text { Oriundo do Gás de Selagem para Vent Atmosférico, } \\
\text { no Caso Base }\end{array}$ \\
\hline
\end{tabular}




\begin{tabular}{|c|c|}
\hline $\mathrm{ECO}_{2}$ gásexpp1 & $\begin{array}{l}\text { Emissão Estimada do } \mathrm{CO}_{2} \text { em Instalações de Produção, Externa a Área } \\
\text { de Concessão do Projeto, na Primeira Proposição }\end{array}$ \\
\hline EOR & Enhanced Oil Recovery \\
\hline EOD & Entidade Operacional Designada \\
\hline $\mathrm{E} \& \mathrm{P}$ & Exploração e Produção \\
\hline EPA & Environment Protect Agency \\
\hline ETS & Emissions Trading Scheme for Greenhouse Gases \\
\hline Etotvab & Emissão Total do Sistema de Vent Atmosférico, no Caso Base \\
\hline Etotgel & $\begin{array}{l}\text { Emissão Total de } \mathrm{CO}_{2} \text { do Sistema de Geração de Energia Elétrica no } \\
\text { Caso Base }\end{array}$ \\
\hline Etotgelp1 & $\begin{array}{l}\text { Emissão Total de } \mathrm{CO}_{2} \text { do Sistema de Geração de Energia Elétrica da } \\
\text { Primeira Proposição }\end{array}$ \\
\hline EtotUCO $\mathrm{Cb}_{2}$ & Emissão Total de $\mathrm{CO}_{2}$ do Sistema de Remoção de $\mathrm{CO}_{2}$, no Caso Base \\
\hline Etotalp1 & $\begin{array}{l}\text { Emissão Total de } \mathrm{CO}_{2} \text { Equivalente do Sistema de Alívio, na Primeira } \\
\text { Proposição }\end{array}$ \\
\hline Etotalb & Emissão Total de $\mathrm{CO}_{2}$ Equivalente do Sistema de Alívio, no Caso Base \\
\hline EVTE & Estudo de Viabilidade Técnico e Econômico \\
\hline $\mathrm{f}$ & Fator de Emissão do Gás Natural \\
\hline $\mathrm{fd}$ & $\begin{array}{l}\text { Fator de Disponibilidade da Torre Contactora da Unidade de Remoção } \\
\text { de } \mathrm{CO}_{2}\end{array}$ \\
\hline feop & $\begin{array}{l}\text { Fator de Eficiência Operacional da Turbina que Possui Sistema de } \\
\text { Captação de Gases de Combustão }\end{array}$ \\
\hline fgn & Fator de Emissão do Gás Natural \\
\hline GLP & Gás liquefeito de Petróleo \\
\hline GEE & Gases de Efeito Estufa \\
\hline GA & Gás Associado \\
\hline GN & Gás Natural \\
\hline GNA & Gás Não-Associado \\
\hline GNV & Gás Natural Veicular \\
\hline GRI & Global Reporting Index \\
\hline GTSP & Global Energy Technology Strategy \\
\hline GWP & Global Warming Potential \\
\hline$G W P_{C H_{4}}$ & Potencial de Aquecimento Global do Metano \\
\hline
\end{tabular}




\begin{tabular}{|c|c|}
\hline $\mathrm{HCs}$ & Hidrocarbonetos \\
\hline $\mathrm{HCNM}$ & Hidrocarbonetos Não Metano \\
\hline HFC & Hidrofluorcarbono \\
\hline HFC-23 & Hidrofluorcarbono 23 \\
\hline IBAMA & Instituto Brasileiro do Meio Ambiente \\
\hline IPCC & Intergovernmental Panel on Climate Change \\
\hline IOR & Improved Oil Recovery \\
\hline ICMS & Imposto sobre Circulação de Serviços e Mercadoria \\
\hline LGN & Líquido de Gás Natural \\
\hline MBRE & Mercado Brasileiro de Emissões \\
\hline MM & Massa Molar do Gás Natural \\
\hline MMC & Massa Molar do Carbono \\
\hline $\mathrm{MMCO}_{2}$ & Massa Molar do Dióxido de Carbono \\
\hline $\mathrm{MMCH}_{4}$ & Massa Molar do Componente Metano \\
\hline MEA & Monoetanolamina \\
\hline MDEA & Metildietanolamina \\
\hline MDL & Mecanismo de Desenvolvimento Limpo \\
\hline MCT & Ministério das Ciências e da Tecnologia \\
\hline MBRE & Mercado Brasileiro de Emissões \\
\hline \multirow[t]{2}{*}{ MDIC } & Ministério do Desenvolvimento, Indústria e Comércio \\
\hline & Exterior \\
\hline MMgáscombb & Massa Molar do Gás Combustível, no Caso Base \\
\hline MME & Ministério das Minas e Energia \\
\hline MP & Material Particulado \\
\hline NAE & Núcleo de Assuntos Estratégicos da Presidência da República \\
\hline NIST & National Institute of Standards and Technology \\
\hline OECD & Organização para a Cooperação e para o Desenvolvimento Econômico \\
\hline O\&M & Operação e Manutenção \\
\hline ONU & Organização das Nações Unidas \\
\hline OPEX & Operational Expenditure \\
\hline $\mathrm{PP}$ & Preparação do Projeto \\
\hline PASEP & Programa de Formação do Patrimônio do Servidor Público \\
\hline PIS & Programas de Integração Social \\
\hline PCI & Poder Calorífico Inferior do Gás Natural \\
\hline
\end{tabular}




\begin{tabular}{|c|c|}
\hline $\mathrm{PCIb}$ & Poder Calorífico Inferior do Gás Natural, no Caso Base \\
\hline PCIp1 & Poder Calorífico Inferior do Gás Combustível da Primeira Proposição \\
\hline PFC & Perfluorcarbono \\
\hline$P \mathrm{i}$ & Pressão Parcial do Componente i \\
\hline$P$ & Pressão Total do Sistema \\
\hline Q & Vazão Mássica do Gás Combustível \\
\hline Q1 & $\begin{array}{l}\text { Vazão Volumétrica de Gás Produzido e de Gás Lift, na Primeira } \\
\text { Proposição }\end{array}$ \\
\hline Q1 & Vazão Volumétrica do Gás Produzido \\
\hline Q2 & Vazão Volumétrica do Gás Produzido e de Gás Lift \\
\hline Q3 & Vazão Volumétrica de Condensado (Gás Equivalente) \\
\hline Q4 & Vazão Volumétrica Total de Gás Combustível (Consumo Próprio) \\
\hline Q5 & $\begin{array}{l}\text { Vazão Volumétrica Referente às Perdas (Sistema de Vent) e Queima de } \\
\text { Gás }\end{array}$ \\
\hline Q6 & Vazão Volumétrica de Gás Produzido Exportado \\
\hline Q7 & Vazão Volumétrica de Gás Armazenado Exportado \\
\hline Q8 & Vazão Volumétrica do Gás Lift \\
\hline Q9 & Vazão Volumétrica Total de Gás Exportado \\
\hline Qap1 & $\begin{array}{l}\text { Vazão Volumétrica do Gás de Selagem dos Compressores Ventilado } \\
\text { pelo Sistema de Vent Atmosférico, na Primeira Proposição }\end{array}$ \\
\hline Qap2 & $\begin{array}{l}\text { Vazão Volumétrica do Gás de Selagem dos Compressores Ventilado } \\
\text { pelo Sistema de Vent Atmosférico, na Segunda Proposição }\end{array}$ \\
\hline Qbp1 & $\begin{array}{l}\text { Vazão Volumétrica de Gás na Corrente de Vent da Unidade de } \\
\text { Remoção de } \mathrm{CO}_{2} \text {, na Primeira Proposição }\end{array}$ \\
\hline Qbp2 & $\begin{array}{l}\text { Vazão Volumétrica de Gás na Corrente de Vent da Unidade de } \\
\text { Remoção de } \mathrm{CO}_{2} \text { na Segunda Proposição }\end{array}$ \\
\hline Qcp1 & $\begin{array}{l}\text { Vazão Volumétrica de } \mathrm{CO}_{2} \text { na Corrente de Alívio do Sistema de Gás } \\
\text { Combustível de Uso Não Energético, na Primeira Proposição }\end{array}$ \\
\hline Qcp2 & $\begin{array}{l}\text { Vazão Volumétrica de } \mathrm{CO}_{2} \text { na Corrente de Alívio do Sistema de Gás } \\
\text { Combustível de Uso Não Energético, na Segunda Proposição }\end{array}$ \\
\hline Qcombneb & $\begin{array}{l}\text { Vazão Volumétrica Total de Gás Combustível de Uso Não Energético } \\
\text { no Caso Base }\end{array}$ \\
\hline Qcombnep1 & $\begin{array}{l}\text { Vazão Volumétrica Total de Gás Combustível de Uso Não Energético } \\
\text { na Primeira Proposição }\end{array}$ \\
\hline
\end{tabular}


Qcombnep2

Qcombnep1

$\mathrm{QCO}_{2}$ entUCO 2 p2

$\mathrm{QCO}_{2}$ capentUCO $\mathrm{UC}_{2} \mathrm{Va}$ que Alimenta uma das Torres Contactora, na Primeira Proposição

$\mathrm{QCO}_{2} \mathrm{entUCO} 2 \mathrm{~b}$

$\mathrm{QCO}_{2}$ tenUCO $2 \mathrm{p} 1$

$\mathrm{QCO}_{2}$ gáscombalb

$\mathrm{QCO}_{2}$ gáscontalb

$\mathrm{QCO}_{2}$ contres1p1

$\mathrm{QCO}_{2}$ contres1p2

$\mathrm{QCO}_{2}$ gnealp1

$\mathrm{QCO}_{2}$ gelb

$\mathrm{QCO}_{2}$ gelp1

$\mathrm{QCO}_{2}$ pentUCO 2 p1

$\mathrm{QCO}_{2}$ tentUCO ${ }_{2} \mathrm{p} 1$

$\mathrm{QCO}_{2}$ cpentUCO $2 \mathrm{p} 1$

Vazão Volumétrica Total de Gás Combustível de Uso Não Energético na Segunda Proposição

Vazão Volumétrica Total de Gás Combustível de Uso Energético, na Primeira Proposição

Vazão Volumétrica de $\mathrm{CO}_{2}$ que Alimenta uma das Torres Contactora, na Segunda Proposição

Vazão Volumétrica de $\mathrm{CO}_{2}$ Presente na Entrada de Uma das Torres Contactora, no Caso Base

Vazão Volumétrica Total de $\mathrm{CO}_{2}$ que Alimenta as Duas Torres Contactoras de $\mathrm{CO}_{2}$, na Primeira Proposição

Vazão Volumétrica de $\mathrm{CO}_{2}$ do Gás Combustível Queimado, no Sistema de Alívio no Caso Base

Vazão Volumétrica de $\mathrm{CO}_{2}$ no Gás de Contingência, no Sistema de Alívio, no Caso Base

Vazão Volumétrica de $\mathrm{CO}_{2}$ do Gás de Contingência Re-injetado no Reservatório Geológico 1, na Primeira Proposição

Vazão Volumétrica de $\mathrm{CO}_{2}$ do Gás de Contingência Re-injetado no Reservatório Geológico 1, na Segunda Proposição

Vazão Volumétrica Anual de $\mathrm{CO}_{2}$, Existente no Gás Combustível de Uso Não Energético, na Primeira Proposição

Vazão Volumétrica Anual de $\mathrm{CO}_{2}$ Existente no Gás Combustível de Uso Energético, no Caso Base

Vazão Volumétrica Anual de $\mathrm{CO}_{2}$ Existente no Gás Combustível de Uso Energético, na Primeira Proposição

Vazão Volumétrica de $\mathrm{CO}_{2}$ Existente no Gás Produzido que Alimenta uma das Torres Contactora, na Primeira Proposição

Vazão Volumétrica Total de $\mathrm{CO}_{2}$ que Alimenta as Duas Torres Contactoras de $\mathrm{CO}_{2}$, na Primeira Proposição

Vazão Volumétrica de $\mathrm{CO}_{2}$ Existente no Gás de Combustão Capturado, que Alimenta uma das Torres Contactoras de $\mathrm{CO}_{2}$, na Primeira Proposição 
$\mathrm{QCO}_{2}$ saidacopinj Vazão Volumétrica de $\mathrm{CO}_{2}$ Existente na Saída do Compressor de Injeção

$\mathrm{QCO}_{2}$ saidaUCO 2 p1 Vazão Volumétrica Total de $\mathrm{CO}_{2}$ na Saída das Duas Torres Contactora, na Primeira Proposição

$\mathrm{QCO}_{2}$ psaidaUCO ${ }_{2}$ p1 Vazão Volumétrica de $\mathrm{CO}_{2}$ Existente no Gás Produzido de Saída de uma das Torres Contactora, na Primeira Proposição

$\mathrm{QCO}_{2}$ cpsaidaUCO ${ }_{2}$ p1 Vazão Volumétrica de $\mathrm{CO}_{2}$ Existente no Gás de Combustão Capturado, de Saída de uma das Torres Contactora de $\mathrm{CO}_{2}$, na Primeira Proposição

$\mathrm{QCO}_{2}$ pentUCO ${ }_{2} \mathrm{p} 2$ Vazão Volumétrica de $\mathrm{CO}_{2}$ Existente no Gás Produzido que Alimenta Uma das Torres Contactora, na Segunda Proposição

$\mathrm{QCO}_{2}$ psaidaUCO ${ }_{2}$ p2 Vazão Volumétrica de $\mathrm{CO}_{2}$ Existente no Gás Produzido de Saída de Uma das Torres Contactora, na Segunda Proposição

QCO 2 gásexpp1 Vazão Volumétrica Anual de $\mathrm{CO}_{2}$ Emitido em Instalações de Produção Externa a Área de Concessão do Projeto, na Primeira Proposição

QCO 2 entbtp1 Vazão Volumétrica Total de $\mathrm{CO}_{2}$ na Entrada do Compressor Booster na Primeira Proposição

QCO 2 entbtp2 Vazão Volumétrica de $\mathrm{CO}_{2}$ na Entrada do Compressor Booster na Segunda Proposição

$\mathrm{QCO}_{2}$ entUCO 2 b Vazão Volumétrica do $\mathrm{CO}_{2}$ Presente na Entrada De Uma das Torres Contactora, no Caso Base

QCO 2 saídaUDESp1 Vazão Volumétrica de $\mathrm{CO}_{2}$ na Saída da Unidade de Desidratação na Primeira Proposição

QCO ${ }_{2}$ saídaUDESp2 Vazão Volumétrica de $\mathrm{CO}_{2}$ na Saída da Unidade de Desidratação na Segunda Proposição

QCO ${ }_{2}$ saídabtp1 Vazão Volumétrica de $\mathrm{CO}_{2}$ na Saída do Compressor Booster, na Primeira Proposição

QCO 2 saídabtp2 Vazão Volumétrica de $\mathrm{CO}_{2}$ na Saída do Compressor Booster, na Segunda Proposição

QCO 2 saídacpinjp1 Vazão Volumétrica de $\mathrm{CO}_{2}$ na Saída do Compressor de Re-Injeção na Primeira Proposição

QCO 2 saídacpinjp2 Vazão Volumétrica de $\mathrm{CO}_{2}$ na Saída do Compressor de Re-Injeção na Segunda Proposição 


\begin{tabular}{|c|c|}
\hline$Q \mathrm{CO}_{2}$ saídaUCO $\mathrm{C}_{2} b$ & $\begin{array}{l}\text { Vazão Volumétrica de } \mathrm{CO}_{2} \text { na Saída de Cada Uma das Torres } \\
\text { Contactora, no Caso Base }\end{array}$ \\
\hline Qcond1stb & $\begin{array}{l}\text { Vazão Volumétrica de Condensado do } 1^{\circ} \text { Estágio dos Compressores, } \\
\text { do Caso Base }\end{array}$ \\
\hline Qcond2stb & $\begin{array}{l}\text { Vazão Volumétrica de Condensado do } 2^{\circ} \text { estágio dos Compressores, do } \\
\text { Caso Base }\end{array}$ \\
\hline Qcond1stp1 & $\begin{array}{l}\text { Vazão Volumétrica de Condensado do } 1^{\circ} \text { Estágio dos Compressores, } \\
\text { da Primeira Proposição }\end{array}$ \\
\hline Qcond2stp1 & $\begin{array}{l}\text { Vazão Volumétrica de Condensado do } 2^{\circ} \text { estágio dos Compressores, da } \\
\text { Primeira Proposição }\end{array}$ \\
\hline Qcond1stp2 & $\begin{array}{l}\text { Vazão Volumétrica de Condensado do } 1^{\circ} \text { Estágio dos Compressores, } \\
\text { da Segunda Proposição }\end{array}$ \\
\hline Qcond2stp2 & $\begin{array}{l}\text { Vazão Volumétrica de Condensado do } 2^{\circ} \text { estágio dos Compressores, da } \\
\text { Segunda Proposição }\end{array}$ \\
\hline$Q \operatorname{descCO} \mathrm{b}$ & $\begin{array}{l}\text { Vazão Volumétrica de } \mathrm{CO}_{2} \text { Ventilado pela Torre Regeneradora no } \\
\text { Caso Base }\end{array}$ \\
\hline QdesUCO ${ }_{2} \mathrm{p} 1$ & $\begin{array}{l}\text { Vazão Volumétrica de Gás que Desvia de Uma das Torres Contactora } \\
\text { da Unidade de Remoção de } \mathrm{CO}_{2} \text {, da Primeira Proposição }\end{array}$ \\
\hline $\mathrm{QdescUCO}_{2} \mathrm{p} 2$ & $\begin{array}{l}\text { Vazão Volumétrica de } \mathrm{CO}_{2} \text { na Saída da Torre Regeneradora, na } \\
\text { Segunda Proposição }\end{array}$ \\
\hline $\mathrm{QdescUCO}_{2} \mathrm{p} 1$ & $\begin{array}{l}\text { Vazão Volumétrica de } \mathrm{CO}_{2} \text { na Saída da Torre Regeneradora, na } \\
\text { Primeira Proposição }\end{array}$ \\
\hline Qentbtp1 & $\begin{array}{l}\text { Vazão Volumétrica Total de Gás na Entrada do Compressor Booster na } \\
\text { Primeira Proposição }\end{array}$ \\
\hline Qentbtp2 & $\begin{array}{l}\text { Vazão Volumétrica Total de Gás na Entrada do Compressor Booster na } \\
\text { Segunda Proposiçãa }\end{array}$ \\
\hline Qentcopinjp1 & $\begin{array}{l}\text { Vazão Volumétrica Total de Gás na Entrada do Compressor de Re- } \\
\text { injeção na Primeira Proposição }\end{array}$ \\
\hline Qentcopinjp2 & $\begin{array}{l}\text { Vazão Volumétrica Total de Gás na Entrada do Compressor de Re- } \\
\text { Injeção na Segunda Proposição }\end{array}$ \\
\hline Qentrada & vazão volumétrica de gás de entrada na Primeira Proposição \\
\hline QentradaCO & Vazão Volumétrica $\mathrm{CO}_{2}$ na Entrada das Torres Contactoras \\
\hline
\end{tabular}


Qgáscapelp1 Vazão Volumétrica do Gás de Combustão Capturado, Oriundo de uma das Turbinas de Geração de Energia Elétrica, da Primeira Proposição

QgáscbnealsCO $\mathrm{CO}_{2}$ 1 Vazão Volumétrica Anual de Gás Combustível, de Uso Não Energético, Isento de $\mathrm{CO}_{2}$, na Primeira Proposição

Qgáscombalb Vazão Volumétrica de Gás Combustível de Uso Não Energético Queimado no Sistema de Alívio, no Caso Base

Qgáscombalp1 Vazão Volumétrica de Gás Combustível de Uso Não Energético Queimado no Sistema de Alívio, na Primeira Proposição

Qgáscombalp2 Vazão Volumétrica de Gás Combustível de Uso Não Energético Queimado no Sistema de Alívio, na Segunda Proposição

QgáscombsCO $\mathrm{C}_{2} \mathrm{alb}$ Vazão Volumétrica de Gás Combustível de Uso Não Energético, Isento de $\mathrm{CO}_{2}$ Queimado, no Caso Base

Qgáscombneab Vazão Volumétrica de Gás combustível de Uso Não Energético Aliviado para atmosfera, no Caso Base

Qgáscombneb Vazão Volumétrica de Gás Combustível Não Energético, queimado no sistema de alívio, no Caso Base

Qgáscontres1p1 Vazão Volumétrica Média de Gás de Contingência Re-Injetado em Reservatório Geológico 1, Por Ano, na Primeira Proposição

Qgáscontres2p1 Vazão Volumétrica Média de Gás de Contingência Re-Injetado em Reservatório Geológico 2, Por Ano, na Primeira Proposição

Qgáscontres1p2 Vazão Volumétrica Média de Gás de Contingência Re-Injetado em Reservatório Geológico 1, Por Ano, na Segunda Proposição

Qgáscontres2p2 Vazão Volumétrica Média de Gás de Contingência Re-Injetado em Reservatório Geológico 2, Por Ano, na Segunda Proposição

QgásentUCO ${ }_{2}$ p1 Vazão Volumétrica de Gás Produzido na Entrada de uma das Torres Contactora, na Primeira Proposição

QgáspsaidaUCO ${ }_{2}$ b Vazão Volumétrica do Gás Produzido na Saída de uma Das Torres Contactora, no Caso Base

QgáspsaidaUCO ${ }_{2}$ p1 Vazão Volumétrica do Gás Produzido na Saída de uma das Torres Contactora da Unidade de Remoção de $\mathrm{CO}_{2}$, na Primeira Proposição

QgáscpsaídaUCO ${ }_{2}$ 1 Vazão Volumétrica do Gás de Combustão Capturado, na Saída de uma das Torres Contactora da Unidade de Remoção de $\mathrm{CO}_{2}$, na Primeira Proposição 
QgáspsaidaUCO $\mathrm{C}_{2}$ 2 Vazão Volumétrica do Gás Produzido na Saída de uma das Torres Contactora da Unidade de Remoção de $\mathrm{CO}_{2}$ na Primeira Proposição

QgásentUCO ${ }_{2}$ p1 Vazão Volumétrica de Gás Produzido na Entrada da Unidade de Remoção de $\mathrm{CO}_{2}$, na Primeira Proposição

Qgásliftp1

Qgáscpelp1

Vazão Volumétrica de Gás Lift da Primeira Proposição

Vazão Volumétrica do Gás de Combustão Capturado, Oriundo de uma das Turbinas de Geração de Energia Elétrica, da Primeira Proposição

QgáscontsCO $\mathrm{CO}_{2} \mathrm{alb}$ Vazão de Gás Queimado, Isento de $\mathrm{CO}_{2}$, em Situações de Contingência, no Caso Base

Qgáscontalb Vazão de Gás Queimado em Situações de Contingência, no Caso Base

QgásentUCO $\mathrm{CO}_{2} \mathrm{~b} \quad$ Vazão Volumétrica do Gás na Entrada de uma das Torres Contactoras da Amina da Unidade de Remoção de $\mathrm{CO}_{2}$, do Caso Base

QgáscentUCO ${ }_{2}$ 1 Vazão Volumétrica de Gás Capturado, na Entrada da Unidade de Remoção de $\mathrm{CO}_{2}$, na Primeira Proposição

Qgásprodb

Qgásprodp1

Vazão Volumétrica do Gás Produzido, do Caso Base

Qgásprodp2

Vazão Volumétrica do Gás Produzido, da Primeira Proposição

Vazão Volumétrica do Gás Produzido, da Segunda Proposição

Qgásselvab

Qgásliftb

Qgásliftp1

Qgásliftp2

Qgáscontres1

Vazão Volumétrica de Gás de Selagem dos Compressores Ventilado pelo Sistema de Vent Atmosférico, no Caso Base

Vazão Volumétrica de Gás Lift, do Caso Base

Vazão Volumétrica de Gás Lift da Primeira Proposição

Vazão Volumétrica de Gás Lift da Segunda Proposição

Vazão Média Diária de Gás de Contingência Armazenado em

Reservatório Geológico 1, por Ano

Qgáscontres2

Vazão Média Diária de Gás de Contingência Armazenado em

Reservatório Geológico 2, por Ano

QgelsCO $\mathrm{CO}_{2}$ 1 Vazão Volumétrica Anual do Gás Combustível, de Uso Energético, Isento de $\mathrm{CO}_{2}$, na Primeira Proposição

Qgásselvab

Vazão Volumétrica de Gás de Selagem, Isento de $\mathrm{CO}_{2}$, Ventilado para Atmosfera, no Caso Base

QgelsCO $\mathrm{C}_{2} \mathrm{~b}$

Vazão Volumétrica Anual de Gás Combustível, de Uso Energético, Isento de $\mathrm{CO}_{2}$, no Caso Base

QgelsCO $\mathrm{CO}_{2}$ 1 Vazão Volumétrica Anual de Gás Combustível, de Uso Energético, Isento de $\mathrm{CO}_{2}$, na Primeira Proposição 
Qgáscombal Vazão de Gás Combustível de Uso Não Energético Queimado no Sistema de Alívio

Qgáscapel Vazão de Gás de Combustão Capturado, oriundo de uma das Turbinas de Geração Elétrica

QgáscpsaídaUCO ${ }_{2}$ 1 Vazão Volumétrica do Gás Capturado na Saída de uma das Torres Contactora da Unidade de Remoção de $\mathrm{CO}_{2}$, na Primeira Proposição

QgáspsaídaUCO ${ }_{2}$ 1 Vazão Volumétrica do Gás Produzido, na Saída de uma das Torres Contactora da Unidade de Remoção de $\mathrm{CO}_{2}$, na Primeira Proposição

QgáspsaídaUCO ${ }_{2}$ 2 Vazão Volumétrica do Gás Produzido, na Saída de uma das Torres Contactora da Unidade de Remoção de $\mathrm{CO}_{2}$, na Segunda Proposição

Qgáscontres1 Vazão Média Diária de Gás de Contingência Armazenado em Reservatório Geológico 1, por Ano

QgásentradaUCO ${ }_{2} \mathrm{~b}$ Vazão Volumétrica de Gás Presente na Alimentação das Torres Contactoras de $\mathrm{CO}_{2}$, do Caso Base

QgássaidaUCO $\mathrm{C}_{2}$ b Vazão Volumétrica de Gás na Saída das Torres Contactoras de $\mathrm{CO}_{2}$, no Caso base

QHCsaídaUDESp1 Vazão Volumétrica de Hidrocarbonetos na Saída da Unidade de Desidratação na Primeira Proposição

QHCentbtp1 Vazão Volumétrica de Hidrocarbonetos na Entrada do Compressor Booster na Primeira Proposição

QHCentbtp2 Vazão Volumétrica de Hidrocarbonetos na Entrada do Compressor Booster na Segunda Proposição

QHCgásnesvab Vazão volumétrica de hidrocarbonetos existentes no gás combustível não energético ventilado, isento de $\mathrm{CO}_{2}$ no Caso Base

QHCgásselvab Vazão volumétrica de hidrocarbonetos existentes no gás de selagem, isento de $\mathrm{CO}_{2}$ no Caso Base,

QHClíqbtp1 Vazão Volumétrica de Hidrocarbonetos Presentes na Fase Líquida, Retirada no Compressor Booster, na Primeira Proposição

QHCsaídabtp1 Vazão Volumétrica de Hidrocarbonetos na Saída do Compressor Booster, na Primeira Proposição

QHClíqbtp1 Vazão Volumétrica de Hidrocarbonetos Presente na Fase Líquida Retirada no Compressor Booster, na Primeira Proposição

QHClíqbtp2 Vazão Volumétrica de Hidrocarbonetos Presentes na Fase Líquida, Retirada no Compressor Booster, na Segunda Proposição 


\begin{tabular}{|c|c|}
\hline QHCap2 & $\begin{array}{l}\text { Vazão Volumétrica de Hidrocarbonetos na Corrente de Vent } \\
\text { Atmosférico, na Segunda Proposição }\end{array}$ \\
\hline QHCbp2 & $\begin{array}{l}\text { Vazão Volumétrica de Hidrocarbonetos na Corrente de Vent da } \\
\text { Unidade de Remoção de } \mathrm{CO}_{2} \text {, na Segunda Proposição }\end{array}$ \\
\hline QHCcp1 & $\begin{array}{l}\text { Vazão Volumétrica de Hidrocarbonetos na Corrente de Alívio do } \\
\text { Sistema de Gás Combustível de Uso Não Energético, na Primeira } \\
\text { Proposição }\end{array}$ \\
\hline QHCcp2 & $\begin{array}{l}\text { Vazão Volumétrica de Hidrocarbonetos na Corrente de Alívio do } \\
\text { Sistema de Gás Combustível de Uso Não Energético, na Segunda } \\
\text { Proposição }\end{array}$ \\
\hline QHCsaídaUDESp2 & $\begin{array}{l}\text { Vazão Volumétrica de Hidrocarbonetos na Saída da Unidade de } \\
\text { Desidratação na Segunda Proposição }\end{array}$ \\
\hline QHCsaídabtp2 & $\begin{array}{l}\text { Vazão Volumétrica de Hidrocarbonetos na Saída do Compressor } \\
\text { Booster, na Segunda Proposição }\end{array}$ \\
\hline QHCentbtp2 & $\begin{array}{l}\text { Vazão Volumétrica de Hidrocarbonetos na Entrada do Compressor } \\
\text { Booster na Segunda Proposição }\end{array}$ \\
\hline QHCsaídacpinjp1 & $\begin{array}{l}\text { Vazão Volumétrica de Hidrocarbonetos na Saída do Compressor de Re- } \\
\text { Injeção, na Primeira Proposição }\end{array}$ \\
\hline QHCsaídacpinjp2 & $\begin{array}{l}\text { Vazão Volumétrica de Hidrocarbonetos na Saída do Compressor de Re- } \\
\text { Injeção, na Primeira Proposição }\end{array}$ \\
\hline QHClíqcpinjp1 & $\begin{array}{l}\text { Vazão Volumétrica de Hidrocarbonetos Líquidos Removidos pelo } \\
\text { Compressor de Re-Injeção na Primeira Proposição }\end{array}$ \\
\hline QHClíqcpinjp2 & $\begin{array}{l}\text { Vazão Volumétrica de Hidrocarbonetos Líquidos Removidos pelo } \\
\text { Compressor de Re-Injeção na Segunda Proposição }\end{array}$ \\
\hline QHCgásselvab & $\begin{array}{l}\text { Vazão Volumétrica de Hidrocarbonetos Existentes no Gás de Selagem, } \\
\text { Isento de } \mathrm{CO}_{2} \text { no Caso Base }\end{array}$ \\
\hline $\mathrm{QH}_{2}$ Oentbtp1 & $\begin{array}{l}\text { Vazão Volumétrica de } \mathrm{H}_{2} \mathrm{O} \text { na Entrada do Compressor Booster na } \\
\text { Primeira Proposição }\end{array}$ \\
\hline $\mathrm{QH}_{2}$ Oentbtp2 & $\begin{array}{l}\text { Vazão Volumétrica de } \mathrm{H}_{2} \mathrm{O} \text { na Entrada do Compressor Booster na } \\
\text { Segunda Proposição }\end{array}$ \\
\hline $\mathrm{QH}_{2}$ Olíqbtp1 & $\begin{array}{l}\text { Vazão Volumétrica de Água Presente na Fase Líquida, Retirada no } \\
\text { Compressor Booster, na Primeira Proposição }\end{array}$ \\
\hline $\mathrm{QH}_{2}$ Olíqbtp2 & $\begin{array}{l}\text { Vazão Volumétrica de Água Presente na Fase Líquida, Retirada no } \\
\text { Compressor Booster, na Segunda Proposição }\end{array}$ \\
\hline
\end{tabular}


$\mathrm{QH}_{2}$ Osaídabtp2 Vazão Volumétrica de $\mathrm{H}_{2} \mathrm{O}$ na Saída do Compressor Booster, na Segunda Proposição

QH ${ }_{2}$ OsaídaUDESp2 Vazão Volumétrica de Água na Saída da Unidade de Desidratação na Segunda Proposição

$\mathrm{QH}_{2}$ Osaídabtp1 Vazão Volumétrica de $\mathrm{H}_{2} \mathrm{O}$ na Saída do Compressor Booster, na Primeira Proposição

QH ${ }_{2}$ OsaídaUDESp1 Vazão Volumétrica de Água na Saída da Unidade de Desidratação na Primeira Proposição

$\mathrm{QH}_{2}$ Olíqbtp1 Vazão Volumétrica de Água Presente na Fase Líquida, retirada no Compressor Booster, na Primeira Proposição

$\mathrm{QH}_{2}$ Oentbtp2 Vazão Volumétrica de $\mathrm{H}_{2} \mathrm{O}$ na Entrada do Compressor Booster na Segunda Proposição

$\mathrm{QH}_{2} \mathrm{Oap} 1$

Vazão Volumétrica de $\mathrm{H}_{2} \mathrm{O}$ na Corrente de Vent Atmosférico, na Primeira Proposição

$\mathrm{QH}_{2} \mathrm{Oap} 2 \quad$ Vazão Volumétrica de $\mathrm{H}_{2} \mathrm{O}$ na Corrente de Vent Atmosférico, na Segunda Proposição

$\mathrm{QH}_{2} \mathrm{Obp1}$ Vazão Volumétrica de $\mathrm{H}_{2} \mathrm{O}$ na Corrente de Vent da Unidade de Remoção de $\mathrm{CO}_{2}$, na Primeira Proposição

$\mathrm{QH}_{2} \mathrm{Obp2}$ Vazão Volumétrica de $\mathrm{H}_{2} \mathrm{O}$ na Corrente de Vent da Unidade de Remoção de $\mathrm{CO}_{2}$, na Segunda Proposição

$\mathrm{QH}_{2} \mathrm{Ocp} 1 \quad$ Vazão Volumétrica de $\mathrm{H}_{2} \mathrm{O}$ na Corrente de Alívio do Sistema de Gás Combustível de Uso Não Energético, na Primeira Proposição

QH $\mathrm{H}_{2} \mathrm{Ocp} 2 \quad$ Vazão Volumétrica de $\mathrm{H}_{2} \mathrm{O}$ na Corrente de Alívio do Sistema de Gás Combustível de Uso Não Energético, na Segunda Proposição

Qlíqbtp1 Vazão Volumétrica de Líquido Retirado no Compressor Booster na Primeira Proposição

Qlíqbtp2 Vazão Volumétrica de Líquido Retirado no Compressor Booster na Segunda Proposição

QmsaídaCO 2 Vazão Mássica de Descarte do $\mathrm{CO}_{2}$ na Torre Regeneradora

Qsaída

Qsaídabtp1

Vazão Volumétrica de Gás de Saída na Primeira Proposição

Vazão Volumétrica de Gás na Saída do Compressor Booster, na Primeira Proposição

QsaídaUDESp1 Vazão Volumétrica de Gás na Saída da Unidade de Desidratação na Primeira 
QsaídaUDESp2 Vazão Volumétrica de Gás na Saída da Unidade de Desidratação, na Segunda Proposição

Qsaídacopinjp1 Vazão Volumétrica de Gás na Saída do Compressor de Re-Injeção, na Primeira Proposição

Qsaídacopinjp2 Vazão Volumétrica Total de Gás na Saída do Compressor de ReInjeção na Segunda Proposição

Qsaídabtp1

Qsaídabtp2

Vazão Volumétrica de Gás na Saída do Compressor Booster, na Primeira Proposição

Vazão Volumétrica de Gás na Saída do Compressor Booster, na Segunda Proposição

QsaídaCO

Qtotreinjres1

Vazão volumétrica de $\mathrm{CO}_{2}$ na Saída da Torre Contactora

Vazão Média Diária Total de Re- Injeção em Reservatório Geológico 1, por Ano

Qtotreinjres1p1 Vazão Volumétrica Média Diária Total de Gás de Contingência ReInjetado em Reservatório Geológico 1, por Ano, na Primeira Proposição

Qtotreinjres2p2 Vazão Volumétrica Média Diária Total de Gás de Contingência ReInjetado em Reservatório Geológico 2, por Ano, na Segunda Proposição

Qtotgnealp1 Vazão Volumétrica Total Anual de Gás Combustível de Uso Não Energético do Sistema de Alívio na Primeira Proposição

Qtotgnealp1 Vazão Volumétrica Total Anual de Gás Combustível Não Energético Enviado para Sistema de Alívio, na Primeira Proposição

Qtotcontactota Vazão Volumétrica Total de Gás a ser Tratado na Torre Contactora Qtotgelb Vazão Volumétrica Anual Total de Gás Combustível de Uso Energético, no Caso Base

Qtotgelp1 Vazão Volumétrica Total Anual de Gás Combustível de Uso Energético na Primeira Proposição

Qtotgelp2 Vazão Volumétrica Total de Gás Combustível de Uso Energético na Segunda Proposição

Qtotgcb Vazão Volumétrica Total de Gás Combustível no Caso Base Vazão Volumétrica Total de Gás Combustível na Primeira Proposição 


\begin{tabular}{|c|c|}
\hline $\mathrm{R}$ & Radical $\mathrm{CH}_{2}$ \\
\hline $\mathrm{RCE}$ & Redução Certificada de Emissão \\
\hline \multirow[t]{2}{*}{ RIO-92 } & Conferência das Nações Unidas sobre Meio Ambiente e \\
\hline & Desenvolvimento Realizado no Rio de Janeiro em 1992 \\
\hline \multirow[t]{2}{*}{$T_{\mathrm{CH}_{4}} b$} & Fração Molar do Componente Metano no Gás Ventilado para a \\
\hline & Atmosfera, no Caso Base \\
\hline TEA & Trietanolamina \\
\hline TIR & Taxa Interna de Retorno \\
\hline TMA & Taxa Mínima de Atratividade \\
\hline $\mathrm{TCO}_{2} \mathrm{ap} 1$ & Teor de $\mathrm{CO}_{2}$ na Corrente de Vent Atmosférico, na Primeira Proposição \\
\hline $\mathrm{TCO}_{2} \mathrm{ap} 2$ & Teor de $\mathrm{CO}_{2}$ na Corrente de Vent Atmosférico, na Segunda Proposição \\
\hline \multirow[t]{2}{*}{$\mathrm{TCO}_{2} \mathrm{bp} 1$} & Teor de $\mathrm{CO}_{2}$ na Corrente de Vent da Unidade de Remoção de $\mathrm{CO}_{2}$, na \\
\hline & Primeira Proposição \\
\hline \multirow[t]{2}{*}{$\mathrm{TCO}_{2} \mathrm{bp} 2$} & Teor de $\mathrm{CO}_{2}$ na Corrente de Vent da Unidade de Remoção de $\mathrm{CO}_{2}$, na \\
\hline & Segunda Proposição \\
\hline \multirow[t]{2}{*}{$\mathrm{TCO}_{2} \mathrm{cp} 1$} & Teor de $\mathrm{CO}_{2}$ na Corrente de Alívio do Sistema de Gás Combustível de \\
\hline & Uso Não Energético, na Primeira Proposição \\
\hline \multirow[t]{2}{*}{$\mathrm{TCO}_{2} \mathrm{cp} 2$} & Teor de $\mathrm{CO}_{2}$ na Corrente de Alívio do Sistema de Gás Combustível de \\
\hline & Uso Não Energético, na Segunda Proposição \\
\hline \multirow[t]{2}{*}{$\mathrm{TCO}_{2}$ cpelp1 } & $\begin{array}{l}\text { Teor de } \mathrm{CO}_{2} \text { existente no Gás de Combustão Capturado, oriundo de } \\
\text { uma das Turbinas de Geração de Energia Elétrica, na Primeira }\end{array}$ \\
\hline & Proposição \\
\hline \multirow[t]{2}{*}{$\mathrm{TCO}_{2}$ gáscbnealp1 } & Teor de $\mathrm{CO}_{2}$ Existente no Gás Combustível de Uso Não Energético na \\
\hline & Primeira Proposição \\
\hline \multirow[t]{2}{*}{$\mathrm{TCO}_{2}$ gáscontalb } & Teor de $\mathrm{CO}_{2}$ do Gás de Contingência que é Queimado pelo Sistema de \\
\hline & Alívio, no Caso Base \\
\hline \multirow[t]{2}{*}{$\mathrm{TCO}_{2}$ gásselvab } & Teor de $\mathrm{CO}_{2}$ Existente no Gás de Selagem Ventilado pelo Sistema de \\
\hline & Vent Atmosférico, no Caso Base \\
\hline \multirow[t]{2}{*}{$\mathrm{TCO}_{2}$ gáscapp1 } & Teor de $\mathrm{CO}_{2}$ existente gás de combustão capturado, oriundo de uma das \\
\hline & turbinas de geração elétrica, na Primeira Proposição \\
\hline \multirow[t]{2}{*}{$\mathrm{TCO}_{2}$ gáscombneb } & Teor de $\mathrm{CO}_{2}$ do Gás Combustível Não Energético Queimado no \\
\hline & Sistema de Alívio, no Caso Base \\
\hline $\mathrm{TCO}_{2} \mathrm{entUCO}{ }_{2} \mathrm{~b}$ & Teor de $\mathrm{CO}_{2}$ do gás que alimenta as Torres Contactoras, no Caso Base \\
\hline
\end{tabular}


$\mathrm{TCO}_{2}$ entUCO $\mathrm{C}_{2} \mathrm{p} 1 \quad$ Teor de $\mathrm{CO}_{2}$ Existente no Gás Produzido de uma das Torres Contactora da Unidade de Remoção de $\mathrm{CO}_{2}$, na Primeira Proposição

$\mathrm{TCO}_{2}$ cpsaídaUCO 2 p1 Teor de $\mathrm{CO}_{2}$ existente no Gás Capturado na Saída de uma das Duas Torres Contactoras, da Unidade de Remoção de $\mathrm{CO}_{2}$, na Primeira Proposição

$\mathrm{TCO}_{2}$ gáscombneb Teor de $\mathrm{CO}_{2}$ do Gás Combustível de Uso Não Energético, no Caso Base

$\mathrm{TCO}_{2}$ gáscombnep1 Teor de $\mathrm{CO}_{2}$ do Gás Combustível de Uso Não Energético Queimado no Sistema de Alívio, na Primeira Proposição

$\mathrm{TCO}_{2}$ gáscombnep2 Teor de $\mathrm{CO}_{2}$ do Gás Combustível de Uso Não Energético Queimado no Sistema de Alívio, na Segunda Proposição

$\mathrm{TCO}_{2}$ gáscontp1 Teor de $\mathrm{CO}_{2}$ do gás de Contingência Queimado pelo Sistema de Alívio na Primeira Proposição

$\mathrm{TCO}_{2}$ gáscontp2 Teor de $\mathrm{CO}_{2}$ do gás de Contingência que é Queimado pelo Sistema de Alívio na Segunda Proposição

$\mathrm{TCO}_{2}$ gáscontres1p1 Teor de $\mathrm{CO}_{2}$ existente no gás de contingência re-injetado no reservatório geológico 1, na Primeira Proposição

$\mathrm{TCO}_{2}$ gáscontres1p2 Teor de $\mathrm{CO}_{2}$ existente no gás de contingência re-injetado no reservatório geológico 1, na Segunda Proposição

$\mathrm{TCO}_{2}$ gásselvab Teor de $\mathrm{CO}_{2}$ Existente no Gás de Selagem Ventilado pelo Sistema de Vent Atmosférico, no Caso Base

$\mathrm{TCO}_{2}$ gásturbelp1 Teor de $\mathrm{CO}_{2}$ existente no Gás Combustível de Uso Energético Consumido pelas Turbinas de Geração de Energia Elétrica, na Primeira Proposição

$\mathrm{TCO}_{2}$ gelb Teor de $\mathrm{CO}_{2}$ Existente no Gás Combustível de Uso Energético, no Caso Base

$\mathrm{TCO}_{2}$ gelp1 Teor de $\mathrm{CO}_{2}$ Existente no Gás Combustível de Uso Energético, na Primeira Proposição

$\mathrm{TCO}_{2}$ psaídaUCO $\mathrm{C}_{2} \mathrm{~b}$ Teor de $\mathrm{CO}_{2}$ existente no Gás de Saída de uma das Torres Contactora

$\mathrm{TCO}_{2}$ psaídaUCO $\mathrm{H}_{2} \mathrm{p}$ Teor de $\mathrm{CO}_{2}$ existente no Gás de Saída de uma das Torres Contactora da Unidade de Remoção de $\mathrm{CO}_{2}$, na Primeira Proposição

$\mathrm{TCO}_{2}$ res1p1 Teor de $\mathrm{CO}_{2}$ Existente no Reservatório Geológico 1 na Primeira Proposição 
Teor de $\mathrm{CO}_{2}$ Existente no Reservatório Geológico 1 na Segunda Proposição

$\mathrm{TCO}_{2}$ saidaUCO $\mathrm{C}_{2} \mathrm{~b}$ Teor de $\mathrm{CO}_{2}$ na Saída das Torres Contactoras de $\mathrm{CO}_{2}$, no Caso Base

$\mathrm{TCO}_{2}$ saídacopinjp1 $\mathrm{O}$ teor de $\mathrm{CO}_{2}$ existente na composição do gás de saída do compressor de Re-injeção na Primeira Proposição

$\mathrm{TCO}_{2}$ saídacopinjp2 Teor de $\mathrm{CO}_{2}$ Existente na Composição do Gás de Saída do Compressor de Re-injeção na Segunda Proposição

$\mathrm{TH}_{2} \mathrm{Oap} 1$

Teor de $\mathrm{H}_{2} \mathrm{O}$ na Corrente de Vent Atmosférico, na Primeira Proposição

$\mathrm{TH}_{2} \mathrm{Oap} 2$

Teor de $\mathrm{H}_{2} \mathrm{O}$ na Corrente de Vent Atmosférico, na Segunda Proposição

$\mathrm{TH}_{2} \mathrm{Obp} 1$

Teor de $\mathrm{H}_{2} \mathrm{O}$ na Corrente de Vent da Unidade de Remoção de $\mathrm{CO}_{2}$, na Primeira Proposição

$\mathrm{TH}_{2} \mathrm{Obp} 2$

Teor de $\mathrm{H}_{2} \mathrm{O}$ na Corrente de Vent da Unidade de Remoção de $\mathrm{CO}_{2}$, na Segunda Proposição

$\mathrm{TH}_{2} \mathrm{Ocp} 1$

Teor de $\mathrm{H}_{2} \mathrm{O}$ na Corrente de Alívio do Sistema de Gás Combustível de Uso Não Energético, na Primeira Proposição

$\mathrm{TH}_{2} \mathrm{Ocp} 2$

Teor de $\mathrm{H}_{2} \mathrm{O}$ na Corrente de Alívio do Sistema de Gás Combustível de Uso Não Energético, na Segunda Proposição

THCap1 Teor de Hidrocarbonetos na Corrente de Vent Atmosférico, na Primeira Proposição

THCbp1 Teor de Hidrocarbonetos na Corrente de Vent da Unidade de Remoção de $\mathrm{CO}_{2}$, na Primeira Proposição

THCcp1

Teor de Hidrocarbonetos na Corrente de Alívio do Sistema de Gás Combustível de Uso Não Energético, na Primeira Proposição

THCap2 Teor de Hidrocarbonetos na Corrente de Alívio do Sistema de Gás Combustível de Uso Não Energético, na Segunda Proposição

THCbp2

Teor de Hidrocarbonetos na Corrente de Vent da Unidade de Remoção de $\mathrm{CO}_{2}$, na Segunda Proposição

THCcp2 Teor de Hidrocarbonetos na Corrente de Alívio do Sistema de Gás Combustível de Uso Não Energético, na Segunda Proposição

UE União Européia

UNFCCC United Nations Framework Convention on Climate Change

UKETS United Kingdom Emissions Trading Scheme

UPGN Unidade de Processamento do Gás Natural 


\begin{tabular}{|c|c|}
\hline VGCBE & $\begin{array}{l}\text { Vazão de Consumo Diário do Gás Combustível de Baixa Pressão de } \\
\text { Uso Energético }\end{array}$ \\
\hline $\mathrm{VGCenergCO}_{2}$ & Vazão Volumétrica Anual de $\mathrm{CO}_{2}$ Queimado \\
\hline VGC & Vazão Anual de Gás de Contingência Queimado \\
\hline VGCenergHC & $\begin{array}{l}\text { Vazão Volumétrica Anual de Queima de Gás Combustível isento de } \\
\mathrm{CO}_{2}\end{array}$ \\
\hline $\mathrm{V}$ & Volume Molar do Gás Natural \\
\hline VventGC & Vazão de Gás Combustível Ventilado \\
\hline VventSL & Vazão de Gás de Selagem dos Compressores \\
\hline VventHC & $\begin{array}{l}\text { Vazão Anual de Gás (Isento } \mathrm{CO}_{2} \text { ) Emitido no Sistema de Vent } \\
\text { Atmosférico }\end{array}$ \\
\hline VventGS & $\begin{array}{l}\text { Volume Anual de Gás de Selagem (Isento } \mathrm{CO}_{2} \text { ) Ventado para } \\
\text { Atmosfera }\end{array}$ \\
\hline VGCAE & $\begin{array}{l}\text { Vazão de Consumo Diário do Gás Combustível de Alta Pressão para } \\
\text { Uso Energético }\end{array}$ \\
\hline VGCenerg & $\begin{array}{l}\text { Vazão Volumétrica de Queima de Gás Combustível de Uso Não } \\
\text { Energético }\end{array}$ \\
\hline VPL & Valor Presente Líquido \\
\hline $\mathrm{WCO}_{2} \mathrm{UCO}_{2}$ & $\begin{array}{l}\text { Emissão Evitada de } \mathrm{CO}_{2} \text { do Sistema de Geração de Energia Elétrica, no } \\
\text { Caso Base }\end{array}$ \\
\hline $\mathrm{WCO}_{2} \mathrm{UCO}_{2} \mathrm{p} 1$ & $\begin{array}{l}\text { Emissão Evitada de } \mathrm{CO}_{2} \text { do Sistema de Geração de Energia Elétrica, na } \\
\text { Primeira Proposição }\end{array}$ \\
\hline $\mathrm{WCO}_{2} \mathrm{CPp} 1$ & Vazão Volumétrica do $\mathrm{CO}_{2}$ capturado na Primeira Proposição \\
\hline $\mathrm{WdescCO}_{2}$ & Vazão Mássica de $\mathrm{CO}_{2}$ na Saída da Torre Regeneradora \\
\hline Wgee & Massa Emitida do Componente Gasoso de Gás de Efeito Estufa \\
\hline
\end{tabular}




\section{LISTA DE SÍMBOLOS}

\begin{tabular}{|c|c|}
\hline $\mathrm{CF}_{4}$ & Perfluormetano \\
\hline $\mathrm{CHF}_{3}$ & Clorofluorcarbono \\
\hline $\mathrm{CFC}$ & Clorofluorcarbono \\
\hline $\mathrm{CH}_{4}$ & Metano \\
\hline $\mathrm{C}_{2} \mathrm{H}_{6}$ & Etano \\
\hline $\mathrm{C}_{3} \mathrm{H}_{8}$ & Propano \\
\hline $\mathrm{C}_{4} \mathrm{H}_{10}$ & Butano \\
\hline $\mathrm{C}_{5} \mathrm{H}_{12}$ & Pentano \\
\hline $\mathrm{C}_{6} \mathrm{H}_{14}$ & Hexano \\
\hline $\mathrm{C}_{7} \mathrm{H}_{16}$ & Heptano \\
\hline $\mathrm{C}_{8} \mathrm{H}_{18}$ & Octano \\
\hline $\mathrm{C}_{9} \mathrm{H}_{20}$ & Nonano \\
\hline $\mathrm{C}_{10} \mathrm{H}_{22}$ & Decano \\
\hline $\mathrm{C} 1$ & Metano \\
\hline $\mathrm{C} 2$ & Etano \\
\hline $\mathrm{C} 3$ & Propano \\
\hline $\mathrm{iC}_{4}$ & Isobutano \\
\hline $\mathrm{nC}_{4}$ & Normalbutano \\
\hline $\mathrm{iC}_{5}$ & Isopentano \\
\hline $\mathrm{nC}_{5}$ & Normalpentano \\
\hline $\mathrm{C}_{6}$ & Hexano \\
\hline $\mathrm{C}_{7}$ & Heptano \\
\hline $\mathrm{C}_{8}$ & Octano \\
\hline $\mathrm{C}_{9}$ & Nonano \\
\hline $\mathrm{C}_{10}$ & Decano \\
\hline $\mathrm{CHF}_{3}$ & Trifluormetano \\
\hline $\mathrm{CF}_{4}$ & Tetrafluormetano \\
\hline $\mathrm{CO}$ & Monóxido de Carbono \\
\hline $\mathrm{CO}_{2}$ & Dióxido de Carbono \\
\hline $\mathrm{COS}$ & Sulfeto de Carbonila \\
\hline $\mathrm{CS}_{2}$ & Dissulfeto de Carbono \\
\hline
\end{tabular}




\begin{tabular}{|c|c|}
\hline $\mathrm{CO}_{3}=$ & Radical Carbonato \\
\hline er & Eficiência de Redução de Emissão \\
\hline$\epsilon a$ & Fração que Representa Excesso de Ar \\
\hline$\epsilon \mathrm{c}$ & Eficiência de Conversão \\
\hline $\mathrm{H}_{2}$ & Hidrogênio \\
\hline $\mathrm{H}_{2} \mathrm{O}$ & Água \\
\hline $\mathrm{HCl}$ & Ácido clorídrico \\
\hline $\mathrm{H}_{2} \mathrm{~S}$ & Gás Sulfídrico \\
\hline $\mathrm{Hg}$ & Mercúrio \\
\hline $\mathrm{He}$ & Gás Hélio \\
\hline$H i$ & Constante de Henry \\
\hline $\mathrm{HCO}_{3}^{-}$ & Radical Bicarbonato \\
\hline $\mathrm{H}^{+}$ & Radical Próton \\
\hline NO & Óxido Nítrico \\
\hline $\mathrm{N}_{2}$ & Nitrogênio \\
\hline $\mathrm{NH}_{3}$ & Amônia \\
\hline $\mathrm{N}_{2} \mathrm{O}$ & Óxido Nitroso \\
\hline $\mathrm{NO}_{\mathrm{x}}$ & Óxido de Nitrogênio \\
\hline $\mathrm{O}_{2}$ & Oxigênio \\
\hline $\mathrm{O}_{3}$ & Ozônio \\
\hline $\mathrm{OH}^{-}$ & Radical Hidroxila \\
\hline $\mathrm{RNH}_{2}$ & Amina Primária \\
\hline$\left(\mathrm{RNH}_{3}\right)_{2} \mathrm{CO}_{3}$ & Sal de Amina Intermediário \\
\hline$\left(\mathrm{RNH}_{3}\right) \mathrm{CO}_{3}$ & Sal de Amina \\
\hline $\mathrm{SO}_{2}$ & Dióxido de Enxofre \\
\hline $\mathrm{SO}_{\mathrm{x}}$ & Óxido de Enxofre \\
\hline $\mathrm{SF}_{6}$ & Hexafluoreto de Enxofre \\
\hline$x \mathrm{i}$ & Fração Molar do Componente "i”" na Fase líquida \\
\hline$y i$ & Fração Molar do Componente "i”" na Fase vapor \\
\hline$\phi i^{v}$ & Coeficiente de Fugacidade da Fase Gasosa \\
\hline$\dot{x}^{l}$ & Coeficiente de Atividade na Fase Líquida \\
\hline
\end{tabular}




\section{LISTA DE UNIDADES}

\begin{tabular}{|c|c|}
\hline atm & Atmosfera \\
\hline bar & Pressão Barométrica \\
\hline bpd & Barris por Dia \\
\hline$\varepsilon / \mathrm{CO}_{2}$ & Euro por Tonelada de Dióxido de Carbono \\
\hline GtC/ano & Giga Tonelada de Carbono por Ano \\
\hline $\mathrm{kg}$ & Quilograma \\
\hline $\mathrm{kg} / \mathrm{d}$ & Quilograma por Dia \\
\hline $\mathrm{kg} / \mathrm{h}$ & Quilograma por Hora \\
\hline $\mathrm{kg} / \mathrm{s}$ & Quilograma por Segundo \\
\hline $\mathrm{kgf} / \mathrm{cm}^{2}$ & Quilogramaforça por Centímetro Quadrado \\
\hline $\mathrm{kcal} / \mathrm{m}^{3}$ & Quilo Caloria por Metro Cúbico \\
\hline $\mathrm{kg} / \mathrm{d}$ & Quilograma por dia \\
\hline kmol & Quilomol \\
\hline $\mathrm{kg} / \mathrm{kmol}$ & Quilograma por Quilomol \\
\hline $\mathrm{kPa}$ & Quilo Pascal \\
\hline $\mathrm{kPa} \mathrm{g}$ & Quilo Pascal Manométrico \\
\hline lb/MMscf & Libra por Milhão de Pé Cúbico na Condição Standard \\
\hline $\mathrm{m}^{3} / \mathrm{d}$ & Metros Cúbicos por Dia \\
\hline $\mathrm{mg} / \mathrm{m}^{3}$ & Miligrama por Metro Cúbico \\
\hline MW & Mega Watt \\
\hline$P$ & Pressão Total do Sistema \\
\hline ppm vol & Parte por Milhão Volumétrico \\
\hline $\mathrm{t} \mathrm{C} / \mathrm{TJ}$ & Tonelada de Carbono por Tera Joule \\
\hline $\mathrm{t} \mathrm{CO}_{2}$ /ano & Tonelada de Dióxido de Carbono por Ano \\
\hline $\mathrm{t} \mathrm{CO}_{2}$ eq./ano & Tonelada de Dióxido de Carbono Equivalente por Ano \\
\hline tep & Tonelada Equivalente de Petróleo \\
\hline $\mathrm{TJ} / \mathrm{m}^{3}$ & Tera Joule por Metro Cúbico \\
\hline $\mathrm{TJ} / \mathrm{d}$ & Tera Joule por Dia \\
\hline $\mathrm{t} \mathrm{CO}_{2}$ & Tonelada de Dióxido de Carbono \\
\hline $\mathrm{t} \mathrm{CO}_{2}$ eq. & Tonelada de Dióxido de Carbono Equivalente \\
\hline $\mathrm{t} \mathrm{CO}_{2} / \mathrm{TWh}$ & Tonelada de Dióxido de Carbono por Tera Watt Hora \\
\hline $\mathrm{t} / \mathrm{h}$ & Tonelada por Hora \\
\hline
\end{tabular}




\begin{tabular}{|c|c|}
\hline $\mathrm{t} / \mathrm{mês}$ & Tonelada por Mês \\
\hline t/ano & Tonelada por Ano \\
\hline $\mathrm{t} \mathrm{CO}_{2}$ eq. & Tonelada de Dióxido de Carbono Equivalente \\
\hline $\mathrm{t} \mathrm{CO}_{2} / \mathrm{TJ}$ & Tonelada de Dióxido de Carbono por Tera Joule \\
\hline \multirow[t]{2}{*}{$\mathrm{t} \mathrm{CO}_{2} \mathrm{eq} . / \mathrm{TJ}$} & Tonelada de Dióxido de Carbono Equivalente por Tera \\
\hline & Joule \\
\hline \multirow[t]{2}{*}{$\mathrm{t} \mathrm{C}-\mathrm{CO}_{2} / \mathrm{TWh}$} & Tonelada de Carbono Expresso em Dióxido de Carbono por \\
\hline & Tera Watt-Hora \\
\hline US\$ & Dólar Americano \\
\hline $\mathrm{US} \$ / \mathrm{t} \mathrm{C}$ & Dólar Americano por Tonelada de Carbono \\
\hline $\mathrm{US} \$ / \mathrm{t} \mathrm{CO}$ & Dólar Americano por Tonelada de Dióxido de Carbono \\
\hline US\$ /bbl & Dólar Americano por barril \\
\hline US\$/boe & Dólar Americano por Barril de Óleo Equivalente \\
\hline US\$/kWh & Dólar Americano por Quilo Watt Hora \\
\hline $\mathrm{US} \$ / \mathrm{m}^{3}$ & Dólar Americano por Metro Cúbico \\
\hline${ }^{\circ} \mathrm{C}$ & Graus Celsius \\
\hline$\% \mathrm{CH}_{4}$ & Percentagem Volumétrica do Metano no Gás Natural \\
\hline$\% \mathrm{C}$ & Percentagem Mássica de Carbono no Gás Natural. \\
\hline$\%$ vol & Percentagem volumétrica \\
\hline$\%$ & Percentagem \\
\hline$£$ & Libra \\
\hline$\varepsilon / \mathrm{t} \mathrm{CO} 2$ & Euro por Tonelada de Dióxido de Carbono \\
\hline
\end{tabular}




\section{SUMÁRIO}

DEDICATÓRIA

AGRADECIMENTOS

RESUMO

ABSTRACT

LISTA DE FIGURAS

LISTA DE TABELAS

LISTA DE ABREVIATURAS E SIGLAS

LISTA DE SÍMBOLOS

LISTA DE UNIDADES

1. INTRODUÇÃO

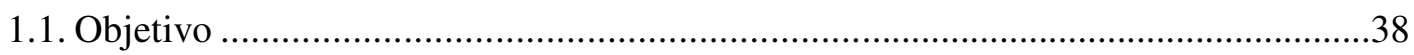

1.2. Originalidade do tema no meio acadêmico e benefícios da pesquisa...................... 38

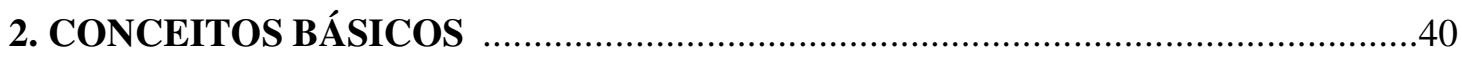

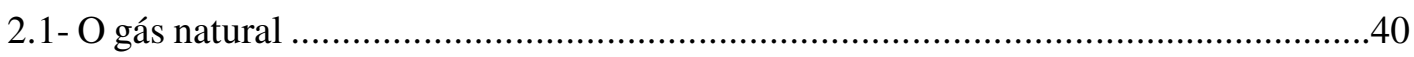

2.1.1- Composição química do gás natural ....................................................................41

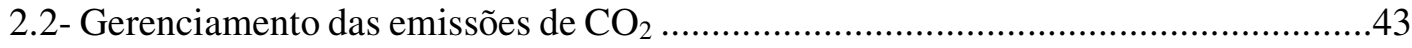

2.2.1- Questão ambiental das emissões atmosféricas ................................................43

2.2.2- Evolução das emissões de $\mathrm{CO}_{2}$ no mundo ....................................................47

2.2.3.- Estimativa das emissões de $\mathrm{CO}_{2}$ em instalações de produção de petróleo

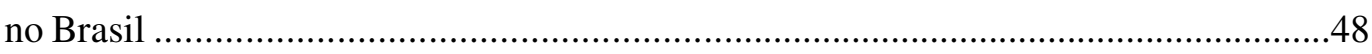

2.2.4- A questão das emissões de $\mathrm{CO}_{2}$ e a Comunidade Internacional ................... 51

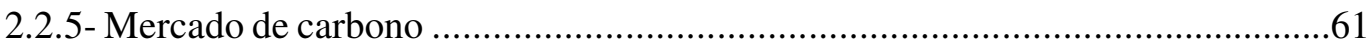

3. ESTADO DA ARTE EM SEPARAÇÃO E CAPTURA DE $\mathrm{CO}_{2}$............................ 64

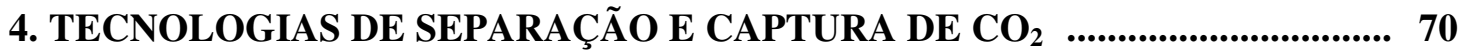

4.1- Combustão do gás natural em turbinas .......................................................... 70

4.1.1- Princípios de funcionamento e construção de turbinas a gás ...................... 71

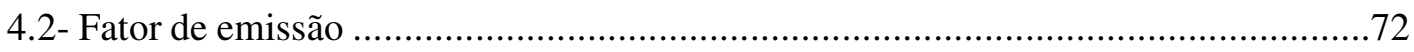

4.3- Tipos de processos de combustão do gás natural .............................................. 74

4.4- Tecnologias de separação e captura de $\mathrm{CO}_{2}$.....................................................76

4.4.1- Absorçãa química .............................................................................77

4.4.2- Absorção física ................................................................................ 80

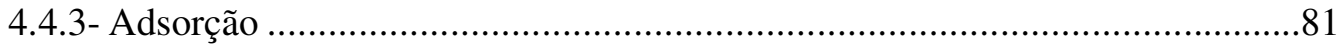


4.4.4- Destilação a baixa temperatura ............................................................... 81

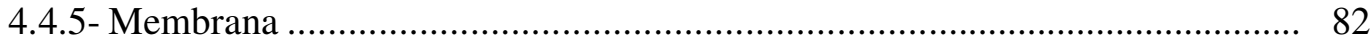

5. METODOLOGIA DO MODELO DE SIMULAÇÃO ........................................... 84

5.1- Descrição sumária da instalação marítima de produção de petróleo ….................. 84

5.1.1 - Descrição sumária do processo de produção ........................................... 86

5.2- Descrição do problema do aumento do teor de $\mathrm{CO}_{2}$ no gás produzido em instalações marítimas de produção de petróleo ........................................................................... 93

5.3. Metodologia do modelo de simulação .............................................................. 95

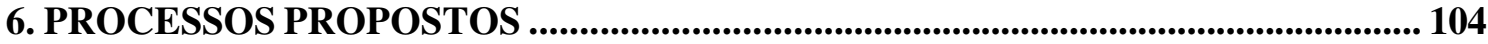

6.1. Descrição dos processos propostos ..................................................................... 104

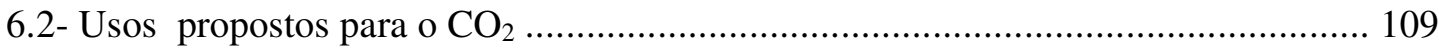

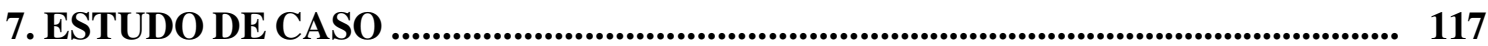

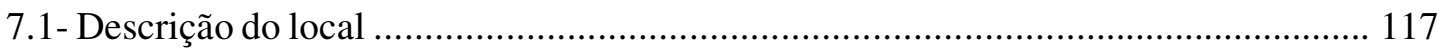

7.2- Elementos técnicos para o estudo das emissões $\quad$............................................. 118

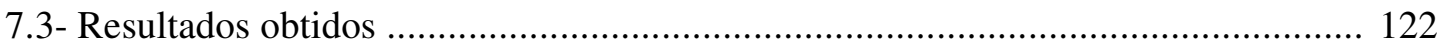

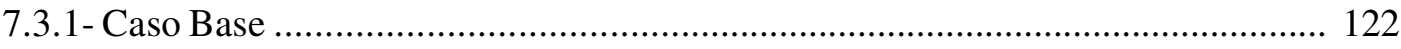

7.3.2- Primeira Proposiçãa …............................................................................ 131

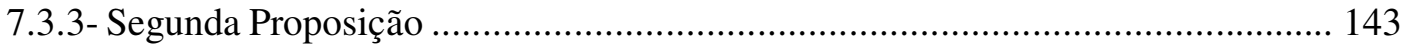

8. VIABILIDADE TÉCNICA E ECONÔMICA ............................................................... 151

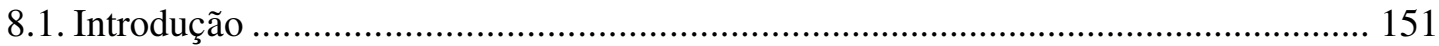

8.2- Dados econômicos e técnicos da Primeira Proposição .......................................... 153

8.3- Dados econômicos e técnicos da Segunda Proposição ......................................... 157

8.4- Premissas e variáveis de entrada do Programa de Análise Econômica ................. 159

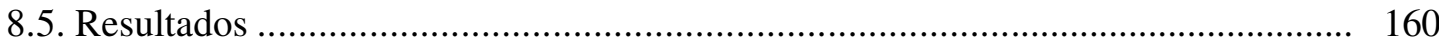

8.5.1- Primeira Proposição ............................................................................. 160

8.5.2- Segunda Proposiçãa …............................................................................ 161

9. CONCLUSÕES E SUGESTÕES PARA TRABALHOS FUTUROS ...................... 162

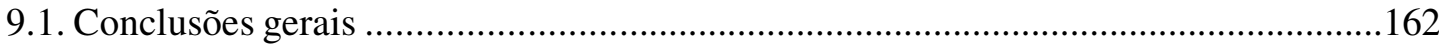

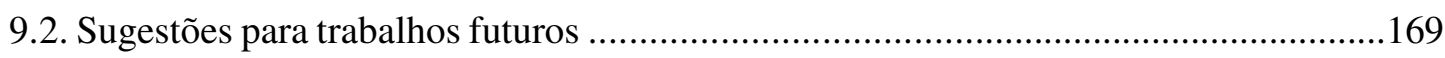

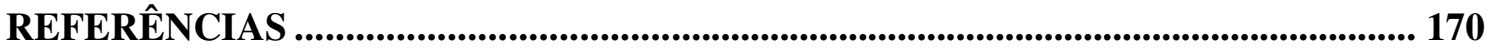

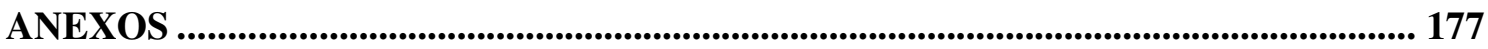

MEMÓRIA DE CÁLCULO ....................................................................................... 180 